\title{
EL DEBATE PARLAMENTARIO Y EL USO DE LA PALABRA
}

FERNANDO SANTAOLALLA LÓPEZ 
SUMARIO

1. IMPORTANCIA DEL DEBATE PARLAMENTARIO. 2. RAZÓN DE SER DEL DEBATE. 3. SU CONSECUENCIA: ÓRGANO COLEGIADO, ASAMBLEARIO. 4. SU UTILIDAD: FORO POLÍTICO POR EXCELENCIA; ESCUELA DE LIBERTAD Y TOLERANCIA. 5. EL DEBATE DEMANDA VOTACIÓN. 6. LOS RASGOS ANTERIORES DIFERENCIAN AL PARLAMENTO DEL GOBIERNO. 7. LAS DIFERENCIAS ORGANIZATIVAS SON EXPRESIVAS DE LA DIVISIÓN DE PODERES. 8. CONDICIONES DEL DEBATE PARLAMENTARIO. 9. USO DE LA PALABRA. 9.1. Solicitud de palabra. 9.2. Carácter personal de las intervenciones en los debates. 9.3. Prohibición de lectura de discursos. 9.4. No interrupción. 9.5. Discursos dirigidos a la cámara o a la presidencia. 10. TURNOS DE PALABRA. LISTA DE ORADORES. 11. USO DEL ESCAÑO O DE LA TRIBUNA. 12. PODERES DEL PRESIDENTE. BIBLIOGRAFÍA CONSULTADA. 


\title{
EL DEBATE PARLAMENTARIO Y EL USO DE LA PALABRA
}

\author{
FERNANDO SANTAOLALLA LÓPEZ \\ Letrado de las Cortes Generales \\ Profesor Titular de Derecho Constitucional (UAH)
}

\section{IMPORTANCIA DEL DEBATE PARLAMENTARIO}

El Parlamento suele ser definido por sus funciones. En este sentido se dice que es el poder legislativo de un país o que es el órgano encargado de la representación del pueblo y del control del Gobierno.

Pero si quisiéramos definir al Parlamento por su forma de actuar, esto es, si quisiéramos responder a la pregunta de cómo trabaja en lugar de a para qué o en qué trabaja, tendríamos que hacerlo afirmando que es una institución deliberante o mejor que es la institución deliberante por excelencia.

Y esto es debido a que el debate, la discusión, son su forma de desarrollar sus funciones. Haga lo que haga, siempre estará presente el debate. Se trate de aprobar leyes, de examinar la actuación del poder ejecutivo o de autorizar los gastos e ingresos del Estado siempre se producirá mediante la deliberación ${ }^{1}$. No hay función parlamentaria que escape a este marco procedimental. Por eso, ya hace tiempo REDLICH definió el gobierno parlamentario como government by talking o gobierno mediante la palabra ${ }^{2}$.

${ }^{1}$ En este sentido C. SCHMITT describió al Parlamento como el lugar donde se realiza la discusión pública de las opiniones políticas. Véase su Teoría de la Constitución, Editorial Revista de Derecho Privado, Madrid, 1934, p. 365.

${ }^{2}$ Por su parte H. LASKI se refirió al gobierno mediante la discusión. Tomo estos últimos datos del estudio preliminar de E. GARCÍA de la obra clásica de W.G. HAMILTON Lógica parlamentaria, Congreso de los Diputados, Madrid, 1996, p. 24. 


\section{RAZÓN DE SER DEL DEBATE}

Si nos preguntamos ahora por la justificación de esta condición deliberante, o sea, el porqué de tener que discutir al ejercer sus funciones oficiales (legislación, control del ejecutivo, aprobación de los presupuestos estatales), caeremos enseguida en la cuenta de que se trata de algo íntimamente asociado a otra característica esencial del Parlamento: su condición de órgano representativo. El Parlamento existe como instancia representativa del pueblo, cuya voluntad forma y sustituye. En este sentido se trata de un órgano consustancial a la democracia: en las dictaduras o no hay Parlamento o hay — todo lo más- un sucedáneo, una mala imitación de lo que supone uno verdadero.

$\mathrm{Al}$ afirmar la naturaleza representativa estamos admitiendo implícitamente otro rasgo de las democracias que el Parlamento asume y refleja: el pluralismo político y social ${ }^{3}$. Se parte de que la sociedad no es uniforme sino dividida por diferencias de opinión, de credos e intereses. Por eso, entre otras cosas, existen diversos partidos políticos y una libertad fundamental es la de crearlos sin cortapisas ni limitaciones innecesarias.

De este modo, al ser la representación parlamentaria una representación de esa sociedad no homogénea, de ese pueblo diverso, forzosamente es en sí misma heterogénea y diversa. Esto explica la pluralidad de grupos políticos o fracciones que se da en todo Parlamento democrático.

Pues bien, esa pluralidad se acompasa perfectamente a la condición de institución deliberante, hasta el punto de que puede decirse que una y otra son cara y cruz de una misma moneda. Si hay debate es porque hay diversidad de opiniones y puntos de vista. Si, por el contrario, hubiese homogeneidad, coincidencia de intereses y de visiones políticas, sobraría el debate, pues estando todos de acuerdo no habría ocasión para discutir, para oponerse a las propuestas o ideas de otro. Viceversa, la diversidad política lleva directamente a polemizar, a discutir sobre las ideas propias y las ajenas. En definitiva, el pluralismo y la diversidad conducen al debate, mientras que éste demanda la existencia de visiones discrepantes.

3 R. MARAÑÓN GÓMEZ, siguiendo a S. TOSSI y J. STUART MILL, habla de la teatralización de la vida política. Véase Dialéctica erística parlamentaria: el debate parlamentario, en ASOCIACIÓN PROFESIONAL DE LETRADOS DE LAS CORTES GENERALES «Bicentenario de la Secretaría y del Cuerpo de Letrados de las Cortes 1811-2011». Cortes Generales, Madrid, 2011, pp. 527 y s. 
El debate parlamentario, como cualquier otro, se construye sobre ideas discrepantes, sobre afirmaciones y negaciones. Como ya advirtió ARISTÓTELES ${ }^{4}$, toda discusión implica a alguien defendiendo algo y a un tercero que se le opone. Se trata de un ejercicio dialéctico, donde se aspira a esclarecer una cuestión, a convencer a alguien de las razones que abonan una determinada visión. En este sentido el Diccionario de la Real Academia de la Lengua (DRAE) define debatir como altercar, contender, discutir, disputar sobre algo.

El debate parlamentario se asemeja al que se produce en un proceso judicial: siempre hay dualidad de partes, demandante y demandado, en nuestro caso partidarios y contrarios o, si se quiere, mayoría y oposición. Y siempre hay una sucesión de argumentos, a los favorables siguen los contrarios, a los afirmativos los negativos. También en ambos casos hay un tercero a quien se aspira a convencer: la ciudadanía en el caso del Parlamento, el juez o tribunal en el caso de un proceso. Como escribió M. KRIELE, la democracia parlamentaria es la transposición de la idea del proceso judicial al proceso político de la legislación 5 .

De otra parte, el debate, el gobierno mediante la discusión, expresa también la superioridad moral de la democracia sobre cualquier otro régimen político. En efecto, partiendo de la diferencia de intereses y puntos de vista inherentes a toda sociedad medianamente desarrollada, la democracia permite que esa discrepancia se encauce y exprese pacíficamente. Mientras que en una dictadura la discrepancia se salda con el sometimiento de todas las opiniones a una sola, la oficial de los gobernantes (il Duce ha sempre la ragione decían los fascistas italianos), en la democracia por el contrario se legitima no solo que todas se expresen sino que compitan entre ellas, con la aspiración última de que al final triunfe la que resulte más convincente. Por eso surge una institución deliberante, de debate, que no es otra que el Parlamento.

La superioridad de este modelo se muestra también en que el debate implica el ejercicio de lo más preciado del ser humano: la inteligencia. Frente a la fuerza bruta del mundo animal, la sociedad civilizada encuentra en el verbo, en el habla que solo tienen los seres racionales, la forma de exponer y resolver sus discrepancias. Mediante la discusión puede esclarecerse racionalmente una cuestión y permitir que los argumentos de más peso se impongan a los de menos. La dialéctica parlamentaria obliga a ejercitar la mente en cuanto implica buscar argumentos y contrargumentos que resulten objetivamente creíbles.

\footnotetext{
${ }^{4}$ En su Retórica escribió: es preciso servirse del discurso para destruir los argumentos contrarios, contra los que se habla como contra alguien que se opone. Véase Libro II, 18, 1391b. Citamos por edición del CEPC, Madrid, 1999, p. 133.

5 Véase Introducción a la teoría del Estado, Ediciones Depalma, Buenos Aires, 1980, pp. 142 y s.
} 


\section{SU CONSECUENCIA: ÓRGANO COLEGIADO, ASAMBLEARIO}

Tanto la naturaleza representativa del Parlamento como su condición de órgano de debate van asociados a otra característica, como es la de tratarse de un órgano más o menos numeroso. Su número exacto varía según los países, pero en general puede decirse que alcanza varios cientos de representantes.

De esta forma, la representación se hace lo suficientemente amplia como para reflejar ese pluralismo social de que antes hablábamos, dando entrada sino a todas al menos a las tendencias más extendidas en una sociedad y a sus diversos intereses territoriales. Con ello se sientan las bases para esa discusión que acompaña a todos los procedimientos parlamentarios. No hay Parlamento sin diversidad interna de fuerzas políticas, cada una con su visión y estrategia, y esto es lo que enciende casi automáticamente esa dialéctica entre unas y otras.

Por eso también es conocido el Parlamento con el sinónimo de «asamblea», en el sentido de órgano colegiado con un número importante de miembros. Y así el DRAE nos da como primera definición de asamblea la de reunión numerosa de personas para discutir determinadas cuestiones y adoptar decisiones sobre ellas. Repárese en esas referencias a la elevada cuantía de componentes y a la finalidad discutidora.

\section{SU UTILIDAD: FORO POLÍTICO POR EXCELENCIA; ESCUELA DE LIBERTAD Y TOLERANCIA}

Todo lo anterior nos aporta uno de los frutos más preciados de esta institución: la de constituir el foro político por excelencia de un país. Quizá este aporte del moderno Parlamento sea el más valioso y auténtico.

Sin duda definen al Parlamento su condición de poder legislativo, que le permite aparecer como autor de las leyes por las que se rige una sociedad; su condición de elector, controlador y censor del Gobierno y finalmente su intervención decisiva en la aprobación de los gastos e ingresos de la misma. Pero estas funciones - innegables e irrenunciables — son en la práctica más nominales que efectivas. Al menos en los sistemas parlamentarios son los gobiernos a través de una implacable disciplina de partido los que dominan la vida interna de las cámaras y los que imponen su voluntad en las cuestiones más importantes. Es muy difícil, por no decir imposible, que se apruebe una ley por el Parlamento contraria a los objetivos del Gobierno o que el primero se resista a autorizar lo que este le demanda. 
Lo que constituye la aportación más genuina y auténtica del Parlamento es este procedimiento de debate y discusión. En este sentido decía M. Hauriou que en las asambleas es más importante el modo de discutir los asuntos que las materias sobre las que éstos versan ${ }^{6}$.

Como las decisiones más importantes (leyes, impuestos, gastos e ingresos) se tienen que adoptar por el Parlamento quiere decirse que todas ellas van a ser discutidas, que todas ellas van a pasar por ese juicio en el que se alternarán posturas a favor y posturas en contra. Esto es lo que convierte al Parlamento en el foro político más importante de un país, o sea en la plataforma donde se exponen públicamente las cuestiones más trascendentales, con argumentos de adhesión o rechazo, y donde las fuerzas políticas con más apoyo popular pueden comprometerse sobre todas y cada una de ellas.

Ya en el siglo XIX W. BAGEHOT apreció esta circunstancia de la que hablamos, citando por delante de la función legislativa del Parlamento a las funciones de servir de intérprete del país, educadora y en fin de expresión de quejas? .

Este foro político permite a los ciudadanos seguir y enterarse del alcance de los problemas sociales, valorar la postura tomada por cada fuerza política y, en especial, la de quienes finalmente deciden, esto es la mayoría. Si sus argumentos no son convincentes o si resultan débiles frente a los aducidos por la oposición, lo más probable es que esa mayoría comience a perder el apoyo de los ciudadanos, que pueden girar entonces su vista hacia otras alternativas y dar lugar a un cambio de preferencias en las siguientes elecciones. Esto es lo que produce la alternancia en el poder, la temporalidad de su ejercicio en una sociedad democrática.

Es verdad que este debate viene marcado por la implacable disciplina de partido político, que conduce a seguir ciegamente las consignas partidarias y a una incapacidad para dejarse convencer ${ }^{8}$. Los alegatos expuestos en un sentido o en otro son más manifestación de los intereses partidarios que resultado de un examen racional y desapasionado del tema de que se trate. Los argumentos que utilizan los parlamentarios son intercambiables, en el sentido de que se esgrimen por unos u otros en función de si se está en el poder o en la oposición: los miembros de la mayoría apoyan siempre las iniciativas gubernamentales mientras que los de la oposición tienen una actitud crítica.

\footnotetext{
${ }^{6}$ Fuente: J. M. GIL-ROBLES y N. PÉREZ-SERRANO «Diccionario de Términos Electorales y Parlamentarios». Taurus, Madrid, 1977, p. 77

7 Véase La constitución inglesa, traducción de A. POSADA, CEPC, Madrid, 2010, pp. 127 y ss.

${ }^{8}$ En este sentido L.M. CAZORLA, La oratoria parlamentaria, Espasa-Calpe, Madrid, 1985, p. 41 .
} 
$\mathrm{Y}$ es que una de las peculiaridades de este debate parlamentario es que es un debate ciento por ciento político, muy alejado del que podría darse en un foro académico, científico o profesional. En el debate parlamentario apenas se aspira a convencer al contrario, puesto que se es consciente de su enorme dificultad, por no decir imposibilidad. A lo que se aspira es a convencer a la ciudadanía a través de la publicidad que es consustancial al debate ${ }^{9}$, atrayéndola hacia sus posiciones con vistas a obtener su voto en las siguientes elecciones. Los discursos de la mayoría buscan reforzar al Gobierno y desacreditar las voces críticas de la oposición. Por el contrario, los discursos de la oposición tratan de convencernos de que la política o la gestión del Gobierno es mala o cuando menos manifiestamente mejorable.

Frente a lo que podría pensarse en una apreciación superficial, el hecho de que el debate se enmarque en estos condicionamientos políticos o que obedezca más a los intereses de grupo que al deseo de esclarecer una cuestión o problema en modo alguno merma su condición de indispensable para la existencia de un Parlamento e, indirectamente, para la vigencia de una verdadera democracia. Pues siempre que se produzca con un mínimo de libertad y autenticidad, la sucesión de argumentos a favor y en contra permite a los ciudadanos formarse una opinión sobre cada asunto, calificar una ley como justa o injusta, o valorar si la gestión de los gobernantes era la debida o por el contrario defectuosa o insuficiente. El debate cumple un papel insustituible pues obliga a la mayoría gobernante a explicar y justificar sus propuestas y decisiones. Las críticas de la oposición son la ocasión para este examen público de la política gubernamental: si son fundadas quedarán manifiestos los yerros o abusos de los que mandan; si son injustificadas o demagógicas podrá apreciarse la justificación de la acción gubernativa $^{10}$.

Vemos así como el debate y la crítica en el seno del Parlamento son piezas esenciales del sistema democrático. Sin ese foro donde concurren y compiten las fuerzas políticas faltaría el dinamismo propio de una verdadera democracia.

Pero al mismo tiempo, este carácter deliberante del Parlamento no sólo es valorable por lo dicho, sino también por constituir una escuela de libertad y

9 Sobre esta interdependencia de debate y publicidad puede verse P. DE VEGA «Las sesiones plenarias de las cámaras» en Comentarios de la Constitución española de 1978, Cortes GeneralesEdersa, Madrid, 1998, T. VI pp. 806 y s.

${ }^{10}$ En este sentido P. DE VEGA, siguiendo a Stuart Mill, afirma que a través de la publicidad los ciudadanos pueden ver proyectadas sus propias opiniones en las opiniones mantenidas por los representantes. Véase «El principio de publicidad parlamentaria y su proyección constitucional» en Revista de Estudios Políticos núm. 43, 1985, pp. 56 y s. 
tolerancia, una referencia de convivencia social ${ }^{11}$. Los individuos que componen una sociedad libre pueden ver todos los días este método de tratar y resolver las diferencias, lo que les llevará a asimilarlo en sus vidas cotidianas. Frente a la imposición coactiva, frente a la consideración sectaria y unilateral de los problemas, el debate parlamentario aporta un modelo continuo que nos estimula a todos a escuchar los argumentos de otros, a ver la realidad desde distintos ángulos, a comprender en fin que las situaciones no son tan simples como a veces nos hace ver nuestro egoísmo o interés.

\section{EL DEBATE DEMANDA VOTACIÓN}

Esta naturaleza deliberativa del Parlamento va unida a otra característica, como es la votación. El debate es consustancial a todos los procedimientos parlamentarios, pero el Parlamento no debate por debatir sino al ejercitar esas funciones que ya hemos mencionado. Por eso es normal que más tarde o temprano ese debate tenga que cerrarse para adoptar una decisión de aprobación o rechazo de la iniciativa debatida.

El pluralismo político que esta presente en el Parlamento hace difícil, como demuestra la experiencia, que pueda surgir una unanimidad, un convencimiento general sobre la solución adecuada en cada propuesta o iniciativa. Las diferencias de estrategia e interés de las fuerzas políticas presentes en las cámaras y las discrepancias ideológicas conducen, por encima del valor de los argumentos empleados en el debate, a que persistan las discrepancias al final del mismo. Esto incluso es la situación más normal.

Por eso la propia lógica (en este sentido J. BENTHAM ${ }^{12}$ ) impone que al final de las discusiones se verifique si la propuesta debatida es aceptada o no, lo que conduce a realizar una votación para conocer de modo seguro el número de adhesiones y rechazos.

De este modo vemos como el pluralismo interno y el carácter deliberativo conducen a esta coda con la que suelen terminar los debates, que es la votación, forma de apreciar si una propuesta se tiene o no por aprobada en función del número de adhesiones recibidas. La propia definición de asamblea del Diccionario de la Academia (supra) ratifica lo que decimos.

${ }^{11}$ En este sentido escribía C. SCHMITT que la discusión es lo humano, lo pacífico, lo progresivo, lo contrario de toda especie de dictadura y poder. Véase su Teoría de la Constitución, Editorial Revista de Derecho Privado, Madrid, 1934, p. 365.

12 Véase su clásica obra Tácticas parlamentarias, reedición de la edición española de 1834, Publicaciones del Congreso de los Diputados, Madrid, 1991, p. 187. 


\section{LOS RASGOS ANTERIORES DIFERENCIAN AL PARLAMENTO DEL GOBIERNO}

Los rasgos que hemos comentado nos dan el perfil más característico del Parlamento, el que ayuda a diferenciarlo de otros órganos constitucionales, especialmente del Gobierno. Este último participa en mayor o menor grado en las funciones oficiales del Parlamento, como la legislativa y la presupuestaria. Así, ejerce la iniciativa legislativa preparando y presentando ante las cámaras proyectos de ley, y elabora también el proyecto de gastos e ingresos del Estado.

En cambio, el Gobierno carece de esa condición de órgano deliberante. Antes al contrario sus decisiones se toman a puerta cerrada y hasta sus componentes juran guardar secreto de lo hablado en sus reuniones. Pues no es misión del Gobierno debatir, en el sentido de debatir coram populo, sino decidir, tomar decisiones. El debate sería en este sentido un elemento contradictorio, puesto que al alargar los procedimientos retrasaría considerablemente la adopción de las decisiones que demanda la cosa pública.

La carencia de naturaleza deliberativa del Gobierno se explica por varias razones. Una de ellas es que no posee la condición representativa popular que en cambio tiene el Parlamento. Cierto es que el Gobierno goza de legitimidad democrática, pues directa o indirectamente ha recibido la confianza popular. Pero no puede equipararse en este sentido al órgano representativo por excelencia, el Parlamento, que da cabida siempre a una composición tan diversa y plural como el propio pueblo al que representa. Esto también hace innecesarios los procedimientos en que el debate y la discrepancia ocupan un lugar preeminente. El debate es hijo de la discrepancia y, a su vez, esta es producto del pluralismo.

Otras circunstancias intervienen también esta situación: la dimensión reducida del Gobierno y su composición homogénea. El Gobierno o Consejo de Ministros es un órgano que en comparación con los varios centenares de miembros del Parlamento cuenta con pocos componentes, raramente supera la veintena. Ello es debido, entre otras razones, a que la decisión impone la ley del pequeño número: solo un colegio reducido puede reunirse con prontitud y adoptar acuerdos en la misma forma. Por eso el Gobierno es la cabeza de un poder del Estado conocido como poder o brazo ejecutivo, esto es, la parte del Estado llamada a adoptar las decisiones básicas y a ejecutarlas.

La carencia de debate se explica también por la composición homogénea o relativamente homogénea del Gobierno. En el caso de los Gobiernos de un solo partido (como ocurre precisamente en España a nivel central), se presenta una visión y unos intereses políticos compartidos, lo que favorece en extremo la coincidencia. Claro está que pueden surgir discrepancias entre los ministros, 
pero estas nunca serán tan fuertes como las que procederían con partidos de la oposición. En el caso de los Gobiernos de coalición, formados entre dos o más partidos políticos, se produce también esta situación, aunque con menos intensidad. Los gobiernos de coalición implican un pacto o acuerdo entre los partidos que los componen, los que les dota de una homogeneidad mínima, especialmente si se compara con los partidos extra-gubernamentales. En la medida que se mantenga ese pacto o acuerdo se mantienen unos intereses comunes que concitan al acuerdo, reduciendo así la necesidad de debatir que como queda dicho es hija de la discrepancia.

Por último, así como a la discusión parlamentaria le sigue la votación, nada de esto se produce en el seno del Gobierno. Es muy raro que se vote dentro de este último, lo que se explica entre otras razones por el hecho ya comentado de la composición homogénea, con miembros que comparten la misma visión política, lo que favorece en extremo la adopción de acuerdos.

\section{LAS DIFERENCIAS ORGANIZATIVAS SON EXPRESIVAS DE LA DIVISIÓN DE PODERES}

Estos rasgos distintivos entre Parlamento y Gobierno son a su vez expresivos del principio clásico de divisiones de poderes, consustancial al Estado de Derecho. La limitación del poder se produce no solo por la distribución de las diversas funciones del Estado, que hasta cierto punto ya sabemos que son nominales, sino precisamente por los rasgos que estamos comentando: el Gobierno, órgano reducido, de composición homogénea es el que adopta las decisiones básicas y lo hace a puerta cerrada, sin debate público. En cambio, el Parlamento es un órgano representativo, de composición plural, que más que decidir lo que hace es controlar y lo hace debatiendo cara a la opinión pública las iniciativas, propuestas y decisiones del primero. El primero no vota para decidir, mientras que el segundo lo hace continuamente.

Estos perfiles procedimentales, tan distintos, aportan también los pesos y contrapesos (checks and balances) en que se basa el Estado constitucional. La división de poderes va íntimamente asociada y se complementa con los diferentes modos de operar de unos y otros. De ahí su importancia.

\section{CONDICIONES DEL DEBATE PARLAMENTARIO}

El debate tiene que respetar dos condiciones básicas para cumplir con el alto papel que le está reservado en el Estado constitucional. Por un lado, tiene que 
ser libre; por otro ordenado. Como se ve, son condiciones de signo opuesto, pero que se reclaman una a otra para producir un resultado de equilibrio ${ }^{13}$.

El debate tiene que ser libre para que se puedan expresar las diversas opiniones existentes en su seno y, de esta forma, la sociedad pueda conocer la postura de cada grupo y los argumentos a favor o en contra de cada iniciativa. Especialmente es importante esta regla desde la perspectiva de la oposición. La misma desarrolla un rol fundamental pues vigila, crítica y controla la acción del Gobierno. Por ello es imprescindible que existan amplias ocasiones de expresión, que el debate se desarrolle sin cortapisas ni restricciones innecesarias.

Pero, por otro lado, el debate tiene que ser mínimamente ordenado. Pues si se produce sin límites, con deliberaciones interminables, se corre el riesgo de paralizar la acción del Estado. Por eso tiene que tener un principio y un fin claros. En el mismo sentido debe estar organizado de tal modo que sirva para esclarecer las cuestiones debatidas, para permitir identificar la posición de cada partido político. Si no hay una sistemática mínima no sólo no se alcanzarán esos objetivos, sino que se trasladará una imagen de confusión, muy negativa para el rol del propio Parlamento.

Como anticipamos, estas condiciones tienen un significado antitético, pues tienden hacia extremos opuestos. Lo que se trata entonces es de combinarlas adecuadamente, para que se produzca un contrapeso entre las mismas. Cada país, cada Parlamento debe ajustar estas premisas a sus propias necesidades, pero teniendo siempre en cuenta que no se puede sacrificar enteramente la una a la otra.

En la organización del debate existen tantos modelos como países, cada uno de ellos contando con reglas peculiares. Pero en general pueden apreciarse dos modelos básicos: el clásico, basado en límites muy reducidos, y el contemporáneo, que implica una ordenación más estricta. El primero, vigente en Europa en el siglo XIX, suponía que los parlamentarios podían hablar cuantas veces quisieran y prácticamente sin límite de tiempo. Primaba por tanto el factor libertad. Ofrecía la posibilidad de agotar un tema, con diversos puntos de vista. Sin embargo, se correspondía con un Parlamento de personalidades individuales y con una carga de trabajo infinitamente inferior a la actual. Por eso resultaba entonces viable. Sin embargo, según fue aumentando el número de iniciativas que debía tramitar el Parlamento se hizo menos recomendable, pues conllevaba la postergación de asuntos pendientes. En el siglo XX se asiste entonces al desa-

13 Otras condiciones y en concreto las materiales, como el espacio físico, las hemos tratado en El Parlamento en la encrucijada. EUDEMA, Madrid, 1989 y en «El foro parlamentario. Una reflexión sobre las salas de plenos y comisiones en algunos parlamentos europeos», en Bicentenario de la Secretaría y del cuerpo de letrados de las Cortes, Asociación de Letrados de las Cortes Generales, Cortes Generales, Madrid, 2011, pp. 279-295. 
rrollo de un nuevo modelo, que intenta ser racionalizador del debate: consciente del abultado número de iniciativas que han de discutirse se organiza el mismo sobre la base de administrar estrictamente el tiempo disponible. Así, se determina el tiempo correspondiente a cada iniciativa y luego dentro de cada una se fija la duración de las intervenciones reservadas a cada grupo parlamentario. Ahora las intervenciones no son exclusivamente individuales, sino referenciadas en mayor o menor medida a los verdaderos protagonistas del trabajo parlamentario, que son los partidos/grupos políticos. Sobre esta cuestión volveremos al tratar de los turnos de palabra.

\section{USO DE LA PALABRA}

A los efectos anteriores, de lograr un equilibrio entre libertad y ordenación de los debates, operan unas reglas sobre el uso de la palabra, reglas que con mayor o menor intensidad se presentan en todos los Parlamentos. A continuación comentamos algunas de estas reglas como son las que se refieren a la solicitud del uso de la palabra, el carácter personal de las intervenciones, las prohibiciones de lectura de los discursos y de interrumpir, el destinatario impersonal de los discursos y el turno de oradores.

\subsection{Solicitud de palabra}

Como dice el artículo 70.1 del Reglamento del Congreso de los Diputados ningún Diputado podrá hablar sin haber pedido y obtenido del Presidente la palabra. Se trata de una medida ordenadora y cuya justificación pocas palabras demanda. Si todos los parlamentarios pudiesen intervenir con solo desearlo, se produciría un caos de intervenciones simultáneas, que impedirían de todo punto el esclarecimiento de la cuestión tratada, con el riesgo añadido de que muchas opiniones quedarían sofocadas por otras.

Por eso es lógico que sólo se pueda hablar cuando el presidente, que actúa en este sentido como un árbitro de los debates, lo disponga. Habrá que esperar entonces el turno correspondiente, según se comenta más abajo. Pero para obtener el uso de la palabra es preciso solicitarlo, lo cual tiene que hacerse en el momento y en la forma oportuna.

Por tanto, el parlamentario debe solicitar el uso de la palabra y no hacer uso de ella hasta que el Presidente la conceda. Esta concesión no puede ser arbitraria, sino sujeta a las normas que rigen en este punto y que se comentan más tarde. El Presidente tiene un margen de discrecionalidad, pero este margen debe 
administrarse siempre con sujeción al reglamento de la Cámara, y buscando lo que es propio del debate: exposición ordenada y equilibrada del mayor número de opiniones posibles.

\subsection{Carácter personal de las intervenciones en los debates}

El apartado 2 del mismo artículo dispone: Los discursos se pronunciarán personalmente y de viva voz.

La primera parte de esta norma (los discursos se pronunciarán personalmente) se corresponde con la condición personalísima del mandato parlamentario, excluyente del imperativo, según resulta del artículo 67.2 de la Constitución (Los miembros de las Cortes Generales no estarán ligados por mandato imperativo). El carácter personal de los discursos parlamentarios viene a significar lo mismo que la exigencia de voto personal e indelegable que recoge el artículo 79.3 de la Constitución. Del mismo modo que nadie puede votar por un diputado o senador o darle instrucciones vinculantes de cómo hacerlo, nadie puede intervenir en nombre de un parlamentario para exponer lo que sólo a él corresponde.

Este inciso —desapercibido en el Reglamento del Congreso- resulta en abierta oposición a una práctica muy consolidada. Se supone que el diputado que hace uso de la palabra manifiesta más que su opinión personal la del grupo a que representa y de hecho así se hace constar. Casi todos los turnos de palabra se consumen como turnos de grupos parlamentarios. De hecho, como luego se expone, el Reglamento prácticamente no admite otra cosa que turnos de portavoces de grupos $^{14}$.

La misma inadecuación manifiesta otra norma, que es consecuencia de la anterior, según la cual los diputados y senadores puedan cederse el turno o derecho a intervenir (artículo 70.4 del Reglamento del Congreso y 84.2 del Reglamento del Senado). Se trata de una previsión de nula aplicación en las Cámaras españolas, probablemente por que se corresponde con un sistema de debate mucho más abierto y personal que el vigente, con turnos restringidos y reservados a los portavoces de los grupos parlamentarios.

\subsection{Probibición de lectura de discursos}

Mayor importancia tiene la referencia del artículo 70.2 a que los discursos se pronuncien de viva voz. Hay cierto recato en esta expresión, sin duda para no

${ }^{14}$ En este sentido resulta más ajustado a la realidad el Reglamento del Senado que calla al respecto. 
poner en aprieto a una realidad contraria bastante extendida. En este sentido es más expresivo y comprometido el artículo 84.1 del Reglamento del Senado que dispone que los discursos ... no podrán, en ningún caso, ser leídos, aunque seráa admisible la utilización de notas auxiliares. Pues, en definitiva, como defiende Cazorla ${ }^{15}$, la exigencia de expresarse de viva voz implica la prohibición como norma general de la lectura de discursos ${ }^{16}$.

Que los discursos se pronuncien de viva voz o, lo que es lo mismo, la prohibición de su lectura se apoya en dos razones básicas.

Por un lado, en la necesidad de impregnar la vida parlamentaria de autenticidad y transparencia. El orador que se expresa sin lectura de un documento demuestra que lo que dice es lo que está en su cabeza. En cambio cuando se lee un discurso no hay forma de asegurar que no sea un tercero el que lo ha redactado, con la consecuencia de que una alocución muy brillante puede ser mérito no del que la realiza sino del que previamente la redactó, que para mayor inri queda en el anonimato.

Una de las exigencias de las democracias es que los ciudadanos puedan valorar la preparación e inteligencia de sus representantes. Por ello se impone que los discursos sean de viva voz, sin lecturas que se prestan a fraudes sobre su autoría. De esta forma quedarán de manifiesto las ideas, capacidad y preparación de los que asumen la función representativa de la sociedad y aspiran a gobernarla. El pueblo tendrá así una prueba valiosísima para confiar o desconfiar de ellos.

No debiera objetarse en contra de lo anterior lo que muchas veces se oye, en el sentido de que si la prohibición de lectura de discursos se aplicase de veras el Parlamento se quedaría sin la presencia de personas con vocación política, de personas con preparación pero que no acostumbradas a hablar en público no podrían expresarse sin un texto escrito. Pues parlamento viene de hablar, de parlar, por lo que se trata de gajes del oficio: el que quiera ser miembro de esa institución tiene que saber que conlleva hablar, expresarse sin lectura de discursos. Si no hay esta aptitud mejor será buscarse otro destino donde satisfacer la vocación política.

En este sentido son muy significativas las palabras de J. BENTHAM: «jamás formará este método — la lectura de discursos — bombres fuertes en una asamblea

15 Véase L.M. CAZORLA en «Comentarios al Reglamento del Congreso de los Diputados». Congreso de los Diputados, Madrid, 2012, pp. 561-564.

16 Indirectamente el artículo 72 del Reglamento del Congreso viene a sentar una prohibición de lectura de discursos pues sólo lo admite en casos concretos: Cualquier Diputado podrá también pedir, durante la discusión o antes de votar, la lectura de las normas o documentos que crea conducentes a la ilustración de la materia de que se trate. La Presidencia podrá denegar las lecturas que considere no pertinentes o innecesarias. 
política; él favorece la inercia del pensamiento y del mismo modo que la costumbre de no andar por su pie produce la indolencia y la poltronería» ${ }^{17}$.

Por lo demás, no se trata de una exigencia excesiva pues cualquier persona de inteligencia media que prepare o estudie un tema podrá manifestarse sobre el mismo sin necesidad de seguir al pie de la letra lo previamente escrito. Debiera aceptarse como una «servidumbre» de la función parlamentaria la de estudiar y conocer con mediana profundidad los temas sobre los que se va a hablar. Esta es la mejor receta, como ya recomendó QUINTILIANO hace muchos siglos, ${ }^{18}$ para posibilitar que los discursos se pronuncien de viva voz. En el mismo sentido P. LAÍN ENTRALGO afirmaba que la primera regla del lenguaje parlamentario es la competencia, esto es, que «sólo debe hablarse en público de lo que se sabe» ${ }^{19}$.

Por lo demás debe partirse de que los debates parlamentarios no son ni necesitan ser debates académicos, con disquisiciones intrincadas o reflexiones metafísicas. El debate parlamentario está destinado al hombre de la calle, al ciudadano corriente, y por eso lo que se requiere no es otra cosa que la de expresarse para que dicho ciudadano - $-\mathrm{y}$ no un colegio de escogidos intelectuales - le pueda entender y seguir. De ahí que lo que se exige con esta norma no es algo que pueda calificarse de excesivo o desproporcionado ${ }^{20}$.

Otra cosa es que el hablar en público demande un mínimo de corrección en la expresión. Esto es, para que cumpla su función deben respetarse las reglas gramaticales y sintácticas que posibilitan la comunicación, el intercambio de opiniones que resulten comprensibles. Pero se convendrá que si esta exigencia se aplica para acceder a numerosas profesiones y oficios con más motivo habrá que hacerlo para una caracterizada por su honorabilidad y dignidad.

Por otro lado, hay una segunda razón que explica la prohibición de lectura de discursos. Y es la necesidad de que el debate responda a lo que más arriba comentamos, esto es, que sea de verdad debate: contraposición de argumentos a favor y en contra, manifestaciones de los que apoyan una iniciativa y de los que se oponen. Se trata de provocar una dialéctica que permita elucidar un tema y

17 Previamente el mismo pensador escribió: «el principal inconveniente de estos discursos escritos es no tener coherencia, enlace ni relación los unos con los otros». Véase J. BENTHAM Tácticas parlamentarias, reimpresión, Congreso de los Diputados, Madrid, 1991, pp. 203 y sigs.

18 Decía QUINTILIANO que "el arte de hablar se basa en el trabajo intenso, en el continuo estudio, en el variado entrenamiento, en numerosísimas experiencias ...» Fuente: SANTIAGO A. LÓPEZ NAVIA El arte de hablar bien y convencer. Temas de hoy, Madrid, 2010, p. 66.

19 Véase P. LAÍN ENTRALGO «Parlamento y lenguaje» en Revista de las Cortes Generales n. ${ }^{\circ} 1,1984$, p. 65 .

${ }^{20}$ En este mismo sentido y de modo muy gráfico afirmaba P. LAÍN ENTRALGO que los «los parlamentarios deben ser hombres que hablen como hombres. No como libros, como hombres». Véase ob. cit. p. 71 . 
de que la ciudadanía pueda extraer sus conclusiones sobre la bondad o maldad de una decisión o sobre la actitud de las distintas fuerzas políticas. Tiene pues un profundo sentido democrático.

Por el contrario la admisión de la lectura de discursos dificulta en buena medida esta dinámica. En su lugar se instaura una sucesión de monólogos, de manifestaciones con escasa conexión entre sí. La lectura de discursos permite al orador transmitir consideraciones acaso brillantes, pero al tratarse de textos previamente redactados se hace prácticamente imposible rebatir argumentos de oradores anteriores. Eso impide que el Parlamento despliegue una de sus principales funciones cara a la sociedad.

Esta sucesión de monólogos hace de los debates parlamentarios algo tedioso, aburrido, que lleva a que le den la espalda no sólo los ciudadanos corrientes, sino los propios integrantes de las Cámaras. Y es que la lectura de cualquier texto casi siempre resulta fría e impersonal, lo que dificulta que despierte interés y sobre todo que el interés se mantenga. En cambio, lo hablado, al ser espontáneo, producto no sólo de la razón sino también del corazón, tiene más posibilidades de atraer y mantener nuestra atención. Lo hablado puede ser menos preciso o riguroso que lo escrito, pues es espontáneo mientras que este es reflexivo, pero en cambio resulta con facilidad más cálido, más humano, y esto es lo que le da una superioridad cuando se trata de debatir políticamente una cuestión. Esto confirma la razón de ser de la prohibición que comentamos ${ }^{21}$.

Desgraciadamente la vida de las Cámaras españolas esta muy alejada de estas exigencias. La verdad es que a pesar del mandato inequívoco de los reglamentos se ha instaurado una práctica en sentido contrario, ya que la lectura de discursos se produce con mucha mayor frecuencia de lo que sería deseable ${ }^{22}$. Parece como si se hubiese impuesto una derogación por uso contrario. De ahí que, a diferencias de épocas pasadas ${ }^{23}$, los debates parlamentarios tiendan a pasar desapercibidos.

Resulta obligado abogar por una vuelta a la ortodoxia parlamentaria, no desde luego por rendir tributo a la tradición o a las formas normativas, sino para que el Parlamento despliegue en plenitud el papel que le corresponde en

21 A mayor abundamiento debían tenerse en cuenta los inconvenientes físicos de la lectura de discursos, que obligan a inclinar la cabeza sobre el texto, dificultando la respiración. Sobre este punto véase A. ORTEGA, «El discurso político», DM, Murcia, 2006, pp. 113 y sigs.

22 Así A. ORTEGA afirma que en vez de Parlamento nuestro Congreso se debía llamar «Lectoramento». Véase ob. cit, p. 101.

${ }^{23}$ Véanse las referencias de nada menos que CANOVAS DEL CASTILLO y SEOANE COUCEIRO, ambos del siglo XIX, sobre la expectación que levantaban las discusiones parlamentarias de la época. Fuente: L.M. CAZORLA La oratoria ..., ob. cit. pp. 56 y s. 
una sociedad democrática. La lectura de discursos lo empobrece mientras que los debates de viva voz le acercan a los ciudadanos, consiguiendo así su fortalecimiento.

De todas formas debe quedar claro que ni los reglamentos ni la lógica parlamentaria excluyen por completo la lectura de textos. Semejante prohibición absoluta seguramente no se practica en ningún país, entre otras razones porque sería inviable. Resulta comprensible —y así lo admite expresamente el artículo transcrito del Reglamento del Senado- la utilización de notas auxiliares o apuntes que le sirvan al orador de guión para su intervención ${ }^{24}$. Pues semejante ayuda no solo no empobrece el debate, sino que lo potencia, al permitir al orador hacer una exposición sistemática, sin el riesgo de olvidar la mención de algún punto o cuestión. Igualmente se comprende perfectamente que el parlamentario que replica a otro anterior pueda tomar nota de lo que este manifiesta para darle contestación puntual.

De otra parte ¿cómo negar que puedan producirse lectura de documentos imprescindibles, como serían informes, dictámenes? Siempre que el tiempo disponible lo permita y sirva para el esclarecimiento de la cuestión debatida puede admitirse la lectura de documentos semejantes, correspondiendo al Presidente de la cámara decidir al respecto. En el mismo sentido ¿cómo impedir que declaraciones delicadas —el programa del Gobierno o compromisos internacionales por ejemplo_ - no sean leídas para poderlas transmitir con la precisión y el rigor que reclaman?

Vemos pues que la prohibición general no se opone a que ciertas manifestaciones sean objeto de lectura. Tendrá que ser el Presidente desde su posición de imparcialidad el que juzgue y decida al efecto. En realidad, la prohibición que comentamos se refiere a los debates en sentido estricto, a las manifestaciones de favor o crítica que provoca una iniciativa parlamentaria, pero no a la iniciativa en sí misma. Por poner otro ejemplo: la prohibición no afecta a la lectura total o parcial de un proyecto de ley, de una o varias enmiendas, de una moción, etcétera. Lo que sí rechaza con carácter general es que las opiniones sobre esas iniciativas se expresen utilizando textos previamente redactados.

${ }^{24}$ De hecho el artículo 72.2 del Reglamento del Congreso viene a decir lo mismo: Cualquier Diputado podrá también pedir, durante la discusión o antes de votar, la lectura de las normas o documentos que crea conducentes a la ilustración de la materia de que se trate. La Presidencia podrá denegar las lecturas que considere no pertinentes o innecesarias.

De idéntico significado es el artículo 33 del Reglamento del Bundestag alemán: se admite solo la lectura de notas. 


\subsection{No interrupción}

Otra regla de los debates parlamentarios es la prohibición de interrumpir al orador que está en el uso de la palabra. Se trata de algo que se justifica por sí mismo: los debates deben ser ordenados, no para sofocar opiniones sino precisamente para que las mismas se puedan expresar y escuchar en toda su extensión. Se supone que posibles opiniones contrarias tendrán su ocasión de manifestarse, por lo que sólo se pide aguardar al turno de cada uno. No hay pues necesidad de interrumpir al que habla.

En este sentido es claro el artículo 70.3 del Reglamento del Congreso de los Diputados: Nadie podrá ser interrumpido cuando hable, sino por el Presidente, para advertirle que se ha agotado el tiempo, para llamarle a la cuestión o al orden, para retirarle la palabra o para hacer llamadas al orden a la Cámara o a alguno de sus miembros o al público. Como se ve, sólo el Presidente que actúa como juez de las discusiones puede interrumpir al orador, pero por motivos tasados y claramente justificados: bien por los excesos del que está en el uso de la palabra (agotamiento del tiempo, apartarse de la cuestión o alterar el orden), bien por los excesos de terceros (llamadas al orden a otro diputado, a la Cámara o al público asistente).

En esta cuestión cabe anotar que no existen en el debate del Congreso muchas ocasiones para manifestar discrepancias, dada la rígida y cicatera ordenación de turnos que establece el Reglamento ${ }^{25}$. Esto podría ser un motivo para las interrupciones. Sin embargo estas no se dan en niveles que podrían calificarse de excesivos, especialmente si se compara la situación con la de otros Parlamentos. Y es que, dejando al margen la disciplina de partido, desde la transición se impuso una cultura parlamentaria que quería huir de las convulsiones y apasionamientos que habían caracterizado el parlamentarismo anterior a la guerra civil y a las que se veía como una de las causas de su fracaso. Por ello puede decirse que en nuestras cámaras reina generalmente la moderación y templanza. No son excesivas las interrupciones y en la misma medida se aplican las medidas correctoras del artículo transcrito.

En cualquier caso, el discrepante siempre tiene a su disposición dos vías, sin necesidad de interrumpir al orador: por un lado, el turno de alusiones (ar-

25 Concretamente el artículo 74 dispone:

1. Si no bubiere precepto específico se entenderá que en todo debate cabe un turno a favor y otro en contra. La duración de las intervenciones en una discusión sobre cualquier asunto o cuestión, salvo precepto de este Reglamento en contrario, no excederá de diez minutos.

2. Si el debate fuera de los calificados como de totalidad, los turnos serán de quince minutos, $y$, tras ellos, los demás Grupos Parlamentarios podrán fijar su posición en intervenciones que no excedan de diez minutos. 
tículo $\left.71^{26}\right)$ y, por otro, más directamente el turno de réplica o rectificaciones (artículo $73^{27}$ ).

A pesar de todo lo anterior, no puede descartarse en una institución política, con discusiones a veces acaloradas y polémicas, que se produzcan interrupciones. Es algo en buena medida comprensible ${ }^{28}$. Pero también lo es la necesidad de reestablecer el orden básico con que deben desarrollarse los debates. Por eso, ante la necesidad de mantener el orden del debate, los reglamentos cuentan con medidas disciplinarias destinadas a cortar posibles excesos. El artículo 103.3 del Reglamento del Congreso prevé que se llame al orden al diputado que con interrupciones o de cualquier otra forma alterare el orden de las sesiones, mientras que el 104 admite que se expulse del salón de sesiones al que hubiera recibido tres llamadas al orden.

En este sentido la intervención del Presidente es decisiva. En su función de juez de los debates debe permitir que se produzcan con la máxima espontaneidad, pero también impidiendo todo aquello que afecte al orden y al decoro de la Cámara y de sus miembros.

\subsection{Discursos dirigidos a la cámara o a la presidencia}

El artículo 84.1 del Reglamento del Senado mantiene la regla tradicional de la oratoria parlamentaria que obliga a que los discursos se dirijan únicamente a la Cámara. La ratio de esta exigencia estriba en no personalizar excesivamente

${ }^{26}$ Este artículo dice: 1. Cuando, a juicio de la Presidencia, en el desarrollo de los debates se bicieren alusiones, que impliquen juicio de valor o inexactitudes, sobre la persona o la conducta de un Diputado, podrá concederse al aludido el uso de la palabra por tiempo no superior a tres minutos, para que, sin entrar en el fondo del asunto en debate, conteste estrictamente a las alusiones realizadas. Si el Diputado excediere estos límites, el Presidente le retirará inmediatamente la palabra. 2. No se podrá contestar a las alusiones sino en la misma sesión o en la siguiente. 3. Cuando la alusión afecte al decoro o dignidad de un Grupo Parlamentario, el Presidente podrá conceder a un representante de aquél el uso de la palabra por el mismo tiempo y con las condiciones que se establecen en los apartados 1 y 2 del presente artículo.

${ }^{27}$ Este artículo dice: 1. En todo debate, el que fuera contradicho en sus argumentaciones por otro $u$ otros intervinientes tendrá derecho a replicar o rectificar por una sola vez y por tiempo máximo de cinco minutos. 2. Lo establecido en el presente Reglamento para cualquier debate se entiende sin perjuicio de las facultades del Presidente para ordenar el debate y las votaciones, oída la Junta de Portavoces, y, valorando su importancia, ampliar o reducir el número y el tiempo de las intervenciones de los Grupos Parlamentarios o de los Diputados, así como acumular, con ponderación de las circunstancias de Grupos y materias, todas las que en un determinado asunto puedan corresponder a un Grupo Parlamentario.

${ }^{28}$ Como afirma E. MAY ciertos ruidos o alborotos pueden llegar a ser irreprimibles. Véase Treatise on The Law, Privileges, Proceedings and Usage of Parliament, 20th edition, Butterworths, Londres, p. 441. 
los debates, por cuanto una discusión centrada en dos parlamentarios puede desembocar en contienda personal, con ataques e imputaciones innecesarias. Al dirigirse el orador no a otro parlamentario concreto, sino al conjunto de los presentes, se favorece que los discursos se mantengan en unos términos objetivos, templados, única forma de que el debate ofrezca todos sus frutos.

En el Parlamento británico se ha exigido tradicionalmente algo aun más riguroso: los discursos deben dirigirse al presidente ${ }^{29}$. Comentando esta regla, escribió J. BENTHAM que al actuar así el diputado que se dirige a un jefe respetado conocerá la necesidad de medir sus expresiones y reprimir los impulsos de ira e indignación ${ }^{30}$. Mejor razonado imposible.

Desgraciadamente ni el Reglamento ni la práctica del Congreso de los Diputados conocen una limitación semejante. A veces se producen intervenciones excesivamente desafiantes de unos oradores con otros, con agrias imputaciones personales $^{31}$, que a nuestro juicio constituyen un mal ejemplo para la ciudadanía. El debate, con todo el ardor y extensión que se requiera, debe encauzarse por caminos más objetivos, pues en definitiva de lo que se trata es de problemas o cuestiones generales, no de asuntos particulares. Por eso reclamaba P. LAÍN mantener una dignidad estética en estos debates ${ }^{32}$.

De ahí que, por ejemplo, al criticar la gestión de un ministro presente sería preferible evitar el usted acusador y la mirada fijada en el mismo para en su lugar hablar del ministro tal o cual y mirar al hemiciclo. $\mathrm{O}$ en vez de decir ustedes hicieron o dejaron de hacer esto o lo otro, mirando ceñudamente a unos bancos concretos, sería preferible hablar siempre de la gestión del partido tal o cual y manteniendo la mirada en la presidencia o en el conjunto del salón de sesiones. En definitiva, críticas todas, tan contundentes como se necesiten, por supuesto de ida y vuelta. Pero evitando que se parezca o que degenere en soez reyerta.

\section{TURNOS DE PALABRA. LISTA DE ORADORES}

Otro aspecto clave de los debates es el de quién y cómo puede intervenir ${ }^{33}$. Como ya adelantamos más arriba, el modelo clásico del debate era el de libertad

29 Véase en este sentido E. MAY Treatise on The Law, Privileges, Proceedings and Usage of Parliament» ob. cit., p. 417.

${ }^{30}$ Véase Tácticas parlamentarias, ob. cit, p. 213.

31 Nos referimos a expresiones como las siguientes: «iusted o ustedes hicieron o dijeron esto o lo otro!; ;mire usted!; ;se lo voy a decir con dos palabras!» Todo ello mirando fijamente al ministro o al diputado al que se dirigen estas expresiones.

32 «Parlamento y lenguaje» ob. cit. p. 66.

33 Véase al respecto M. CAVERO GÓMEZ, Sesiones parlamentarias: debate y publicidad, en Los 
prácticamente completa: todos los miembros de las cámaras podían hacer uso de la palabra, eso sí, solicitándolo y aguardando su turno, todo ello bajo la dirección del presidente de la cámara.

Otro modelo es el racionalizado u organizador, surgido en tiempos mucho más recientes. Se trata de establecer normativamente el número de turnos de palabra, su duración y sus beneficiarios. Se llega incluso a cronometrar el tiempo que corresponde a cada orador. Es una consecuencia de la multiplicación del número de iniciativas que hay que tramitar, que obliga a repartir el tiempo disponible entre cada una de ellas.

El modelo clásico, con diversos matices y retoques, se mantiene en muchos Parlamentos europeos. Así en la Cámara de los Comunes ${ }^{34}$, el speaker concede la palabra según la piden los diputados, los cuales se hacen notar a este respecto (catching the speaker's eye), incluso con aviso previo. Pero el speaker dispone de discrecionalidad en el otorgamiento de la palabra, y lo hace alternando turnos a favor y en contra de miembros de la mayoría y de la oposición, dando cierta preferencia a los frontbenches sobre los backbenches. El debate es en principio ilimitado, sin topes sobre el número de turnos o su duración. Pero existen dos poderosos contrapesos que eventualmente evitan una prolongación excesiva: por un lado, la moción de cierre (closure), que si se aprueba por la Cámara obliga a concluir un debate concreto. Es un arma de la mayoría, pero el speaker puede rechazarla cuando la estime abusiva. Por otro, las mociones de guillotina, por las que se adjudica un tiempo máximo de discusión a un proyecto de ley o parte del mismo. Un tercer procedimiento es la selección de enmiendas por el speaker, que este realiza sometiendo a debate las más significativas y evitando las de escasa importancia o repetitivas.

En Italia también parece seguirse un procedimiento cercano al clásico ${ }^{35}$. Se emplea a estos efectos la lista de oradores, en la que deben inscribirse los diputados que desean intervenir, haciéndolo al menos una hora antes del inicio del debate del asunto correspondiente (art. 36.1 del Reglamento de la Cámara de diputados $\left.{ }^{36}\right)$. No hay por tanto limitación estricta de turnos de palabra, si bien

Parlamentos de Europa y el Parlamento Europeo, J. M. GIL-ROBLES GIL-DELGADO (dir.), Proyectos y Producciones Editoriales, Madrid, 1997, pp. 178 y ss.

${ }^{34}$ Para lo que sigue véase E. MAY Treatise on The Law, Privileges, Proceedings and Usage of Parliament» ob. cit. pp. 417-424 y 451-467.

35 No obstante, la presencia de los grupos políticos se deja notar. Véase en este sentido A. MANNINO, «Diritto Parlamentare», Guiffrè Editore, Milán, 2010, pp. 230 y ss.

${ }^{36}$ I deputati che intendono parlare in una discussione devono iscriversi entro il giorno in cui questa ha inizio ed hanno la parola nell'ordine dell' iscrizione, alternativamente contro e a favore. Se è stato approvato il calendario dei lavori a norma dell'articolo 24, le iscrizioni a parlare nella discussione sulle linee generali 
cada diputado solo puede intervenir una vez en la misma discusión (art. 43.1 del Reglamento de la Cámara). La duración de los turnos de palabra es generosa, por cuanto llega a los 30 minutos $^{37}$.

El modelo racionalizado u organizado lo encontramos en Francia ${ }^{38}$. La discusión de los proyectos de ley comienza con una discusión de totalidad cuya duración viene fijada por la Conferencia de presidentes, duración que a su vez se reparte entre los grupos por una regla de proporcionalidad corregida, que garantiza un tiempo mínimo incluso a los grupos pequeños. El tiempo asignado a cada grupo puede utilizarse por varios diputados, pero lo normal es que el portavoz sea el primero y el que más hable. Luego se procede al debate del articulado, donde rigen unas reglas más abiertas: respecto a cada artículo todo diputado que lo desee puede hacer uso de la palabra, bien que tan solo por dos minutos, inscribiéndose en la lista de oradores (art. 54.2 del Reglamento de la Asamblea Nacional ${ }^{39}$ ). A continuación se discuten una a una las enmiendas, momento en el que pueden intervenir el enmendante individual, el presidente o ponente de las comisiones que han tramitado o informado la iniciativa, el gobierno y otro diputado en contra. A su vez, cabe responder al gobierno o a la comisión en un nuevo turno. Pero el procedimiento puede aligerarse cuando la Conferencia de presidentes aprueba el recurso al tiempo legislativo programado, que otorga tiempos máximos de discusión no solo para la totalidad sino también para los artículos. En ese caso cada grupo se tiene que ajustar al tiempo asignado.

Otro ejemplo de ordenación de los debates lo encontramos en el Parlamento Europeo $^{40}$. El tiempo de uso de la palabra se distribuye de la manera

di un argomento compreso nel calendario stesso devono intervenire non meno di un'ora prima dell' inizio della discussione.

37 En este sentido el artículo 39 dispone: Salvo i termini più brevi previsti dal Regolamento, la durata degli interventi in una discussione non può eccedere i trenta minuti.

38 Para lo que sigue véase Fiche n. ${ }^{\circ} 36$ : La séance plénière en http://www.assemblee-nationale.fr/connaissance/fiches_synthese/fiche_36.asp

39 Les députés qui désirent intervenir s'inscrivent auprès du Président qui détermine l'ordre dans lequel ils sont appelés à prendre la parole.

${ }^{40}$ En concreto el artículo 149 de su Reglamento dispone lo siguiente: la Conferencia de Presidentes puede proponer al Parlamento la distribución del tiempo de uso de la palabra, sobre lo que decide el propio Parlamento sin debate. El Presidente de la Cámara puede elaborar, para la primera parte del debate, una lista de oradores con una o más rondas de oradores pertenecientes a cada grupo político que deseen hacer uso de la palabra, por orden de tamaño del grupo político, así como a un diputado no inscrito. El tiempo de uso de la palabra para esta parte del debate se distribuye con arreglo a los criterios siguientes: a) la primera fracción en partes iguales entre todos los grupos políticos; b) la segunda fracción se prorratea entre los grupos políticos en proporción al número de sus miembros; c) se atribuye globalmente a los no inscritos un tiempo calculado según las fracciones asignadas a cada grupo político conforme a las letras a) y b). Además, si se acuerda una 
siguiente: una primera fracción en partes iguales entre todos los grupos políticos, y después una segunda fracción se prorratea en proporción al número de sus miembros. Los diputados que piden la palabra son inscritos en una lista de oradores según el orden de importancia numérica de sus respectivos grupos. No obstante, puede concederse un turno prioritario de palabra a los ponentes de la comisión competente y de las comisiones consultadas para opinión. Además, tras las votaciones cabe requerir un turno de explicación de voto.

$\mathrm{Al}$ modelo organizador también corresponde el caso español. Es más, se trata de una organización extrema, en el sentido de excesivamente restrictiva, con sacrificio casi completo de las posiciones individuales ${ }^{41}$. Realmente lo que impera es una concepción autoritaria, que opera en un doble sentido: por un lado, en la mayoría de las ocasiones solo se admiten turnos de portavoces, con lo que el diputado que no ostenta esta condición se ve impedido de dar su opinión; por otro, aunque con excepciones en los asuntos importantes, cada grupo dispone de un solo turno.

La regulación es escasa y desde luego muy limitativa de las ocasiones de participación. Así, el artículo 74.1 del Reglamento del Congreso dispone como norma general la de un solo turno a favor y otro en contra con una duración que no excederá de diez minutos. Pero si el debate fuese de totalidad la duración se amplia hasta los quince minutos, con posteriores turnos de fijación de posiciones de grupos de diez minutos.

La praxis ha generado sus propios precedentes, también en sentido muy limitativo. Por referirnos a uno de los casos más destacados, como los debates legislativos, puede decirse que tanto en comisión como en el pleno se sustancian en un único turno de portavoces ${ }^{42}$, donde el representante de cada grupo expone

distribución global del tiempo de uso de la palabra para varios asuntos del orden del día, los grupos políticos deben notificar al Presidente la fracción de su tiempo que se proponen dedicar a cada uno de los asuntos. La parte restante del tiempo de debate no se asigna específicamente por anticipado. En su lugar, el Presidente llama a los diputados a intervenir, como norma general, durante no más de un minuto, velando en la medida de lo posible por que se escuche consecutivamente a oradores con diferentes opiniones políticas y procedentes de distintos Estados miembros. Cuando lo soliciten pueden obtener prioridad el presidente o el ponente de la comisión competente y los portavoces de los grupos políticos. Además, el Presidente puede conceder el uso de la palabra a los diputados que indiquen, mostrando una tarjeta azul, su voluntad de formular una pregunta que no supere medio minuto de duración a otro diputado, durante la intervención de este, siempre que el orador manifieste su acuerdo y que el Presidente entienda que ello no altera el desarrollo del debate.

41 En sentido parecido D. LÓPEZ GARRIDO, Los debates parlamentarios en Parlamento y derecho [seminario sobre derecho parlamentario, celebrado los días 1 a 3 de marzo de 1990] A. FIGUEROA LARAUDOGOITIA y J. C. DA SILVA OCHOA (coords.). Parlamento Vasco, Vitoria-Gasteiz, 1991, p. 390.

42 Esta práctica se aparta claramente del artículo 114.1 del Reglamento del Congreso que prevé que el debate en comisión se haga artículo por artículo. 
de una sola vez su visión sobre el texto tramitado, defiende sus enmiendas y, en su caso, critica las de los otros grupos ${ }^{43}$.

$\mathrm{Al}$ comprimirse en tan alto grado los turnos de palabra, los debates tienden a ser fugaces, incluso en iniciativas importantes. Por eso casi nunca se hace necesario recurrir al cierre del debate que como testimonio de otra época conserva el Reglamento ${ }^{44}$.

También del modelo clásico se ha conservado la facultad del Gobierno de poder intervenir siempre que lo deseen sus miembros ${ }^{45}$. Esta facultad resultaba enteramente lógica en épocas anteriores, en las que se podían producir múltiples manifestaciones de diputados sobre una misma cuestión, lo que exigía una contestación adecuada del Gobierno: a cada crítica recibida debía corresponder una ocasión de defensa. Pero hoy día, dados los limitados turnos de palabra de los diputados, se comprende mucho menos.

Además, la duración de los turnos gubernativos tiende a administrarse con una flexibilidad que no siempre se ofrece a los grupos. La igualdad de armas procesales demandaría que los turnos del Gobierno se atemperasen a los que disfruten los parlamentarios, no más. Sin embargo, no hay tal: el primero está claramente favorecido. El resultado final es un debate bastante desequilibrado, donde el Gobierno dispone de más oportunidades de defender su política que las que tiene la Cámara para criticarla o controlarla.

En definitiva, puede decirse que la regulación y la praxis del debate en el Congreso de los Diputados son bastante deficientes. Su cortedad y abigarramiento dificultan en extremo que el debate ofrezca todas las potencialidades de las que ya hemos hablado. A nuestro modesto juicio es uno de los aspectos que necesitan una pronta y profunda reforma.

43 Así lo reconoce P. GARCÍA-ESCUDERO El procedimiento legislativo ordinario en las Cortes Generales, CEPC, Madrid, 2006, p. 418.

${ }_{44} \mathrm{El}$ artículo 76 dice: El cierre de una discusión podrá acordarlo siempre la Presidencia, de acuerdo con la Mesa, cuando estimare que un asunto está suficientemente debatido. También podrá acordarlo a petición del portavoz de un Grupo Parlamentario. En torno a esta petición de cierre podrán hablar, durante cinco minutos como máximo cada uno, un orador en contra y otro a favor.

Esta inadecuación de viejas reglas con el draconiano sistema actual se manifiesta también en otras normas, como la cesión del turno de palabra entre varios diputados (art. 70.4). Tal posibilidad se correspondía con un sistema de lista abierta de oradores, donde podían inscribirse todos los interesados. Así al tener cada uno un turno asegurado se comprendía su cesión a otro colega. La inadecuación se comprueba en su completo desuso.

${ }^{45}$ El artículo 70.5 del Reglamento del Congreso dispone: Los miembros del Gobierno podrán bacer uso de la palabra siempre que lo soliciten, sin perjuicio de las facultades que para la ordenación de los debates corresponden al Presidente de la Cámara. 
Esta regulación y esta praxis proceden del tiempo de la transición y poco tienen que ver con el mejor parlamentarismo histórico español. Anteriormente regía un sistema de mucha mayor libertad y probablemente ello permitió un gran desarrollo de la oratoria parlamentaria ${ }^{46}$. Por solo citar un ejemplo, en 1921 se tramitó en el Congreso de los Diputados el proyecto de ley de ordenación bancaria. Su debate ocupó el final de octubre, todo el mes de noviembre y la mayor parte de diciembre, por supuesto del Pleno ${ }^{47}$.

\section{USO DEL ESCAÑO O DE LA TRIBUNA}

Acerca del lugar desde donde se pronuncian los discursos se conocen varias soluciones: uso del escaño exclusivamente, uso de la tribuna o, lo que es bastante corriente, alternar según los casos ambas posibilidades.

La primera solución es la aplicada tradicionalmente en el Parlamento británico $^{48}$, hasta el punto de que no existe tribuna. Todos los diputados hablan desde su escaño, con la única diferencia de que los dirigentes ocupan los front benches mientras que los que no lo son ocupan los bancos traseros (backbenches).

En las cámaras francesas no existe regla al respecto, pero el uso parlamentario lleva a distinguir entre los debates sobre las cuestiones generales de los textos legislativos y los relativos al articulado. En los primeros los diputados y senadores hacen uso de la tribuna existente debajo de la presidencia de la cámara. En cambio, en el debate sobre los artículos y enmiendas intervienen desde el escaño. Esta última modalidad se emplea también en las preguntas orales al Gobierno ${ }^{49}$.

En el Bundestag alemán su reglamento admite que se utilicen los lugares del salón de sesiones donde están instalados micrófonos o la tribuna central (art. 33: Die Redner sprechen von den dafür bestimmten Saalmikrofonen oder vom Rednerpult aus). Resulta frecuente la utilización de la tribuna. En cambio, las preguntas se exponen desde el escaño.

46 Véase al respecto F. AYALA Prólogo a la obra de L. CAZORLA La oratoria ..., ob. cit. pp. 9 y s. También J.M. CUENCA TORIBIO Estudio introductorio en La oratoria parlamentaria española: una antología Madrid, Boletín Oficial del Estado-Centro de Estudios Políticos y Constitucionales, 2002. Este autor (p. 45) califica de apogeo y auge de la oratoria el periodo del sexenio democrático y la restauración.

${ }^{47}$ Fuente: J. PABÓN, Cambó, Editorial Alpha, Barcelona, 1969, vol. II, p. 322.

48 Véase E. MAY, Treatise on The Law, Privileges, Proceedings and Usage of Parliament» ob. cit. p. 418.

49 No obstante, en otros debates de control más prolongados, los parlamentarios pueden escoger entre el escaño y la tribuna. 
En las cámaras españolas también se utilizan la tribuna y los escaños. La primera con carácter general, mientras que los segundos tienen su principal manifestación en las preguntas orales al Gobierno.

De este modo podemos concluir que en este concreto aspecto existe una importante diferencia entre lo observado en el Reino Unido y lo observado en el continente. La ventaja del sistema británico es que confiere más espontaneidad y dinamismo a los debates, pues se desarrollan en un ambiente directo y sin las interrupciones a que obliga el uso de la tribuna. Este último confiere mucha más solemnidad y rigidez. Pero a cambio ayuda a centrar la atención en el orador que está en el uso de la palabra.

\section{PODERES DEL PRESIDENTE}

Si todo foro de discusión necesita la presencia de un moderador que encauce los debates, con mucha más razón se necesita esta intervención en los debates parlamentarios: las cámaras son asambleas muy numerosas, donde se tratan arduas cuestiones que afectan a intereses y credos políticos. Por ello es relativamente fácil que la pasión se desborde, que se produzcan incidentes.

Se hace entonces necesario recuperar el orden que permita el pacífico desarrollo de las deliberaciones y para ello no hay mejor árbitro que el presidente de la cámara. Por un lado, solo un órgano individual puede responder de modo inmediato a los incidentes que pueden surgir en el curso de una sesión. Por otro, al haber sido elegido por la cámara, el presidente goza de una clara autoridad moral que le capacita para dirigir los debates, incluso imponiendo correcciones y sanciones.

Esta faceta del presidente es una de las más características suyas. Condición indispensable es ejercerla como verdadero árbitro, con espíritu institucional, lo que significa olvidar las preferencias de partido y actuar con imparcialidad y sometimiento al reglamento.

En este punto existe una coincidencia bien expresiva de los reglamentos parlamentarios. Por poner unos ejemplos, el artículo 7.1 del Reglamento del Bundestag le atribuye, entre otras cosas, la dirección equitativa e imparcial de los debates $^{50}$. Por su parte, el Reglamento de la Asamblea Nacional francesa otorga al presidente dirigir sus deliberaciones, hacer observar el reglamento y mantener el orden pudiendo en cualquier momento suspender o levantar la sesión ${ }^{51}$. En la

${ }^{50}$ En concreto afirma: Der Präsident... leitet die Verhandlungen gerecht und unparteiisch und wahrt die Ordnung im Hause.

${ }^{51}$ En concreto el artículo 52.1 dice: Le Président ouvre la séance, dirige les délibérations, fait observer le Règlement et maintient l'ordre ; il peut, à tout moment, suspendre ou lever la séance. 
Cámara de los Comunes, aunque la última palabra corresponde a la propia cámara, el speaker actúa como autoridad ejecutiva que aplica las normas ${ }^{52}$. Finalmente, el artículo 32.1 del Reglamento del Congreso de los Diputados establece que el Presidente del Congreso ostenta la representación de la Cámara, asegura la buena marcha de los trabajos, dirige los debates, mantiene el orden de los mismos...

El presidente dispone de varios poderes para cumplir su misión. Nos referiremos a los más importantes: llamada a la cuestión, llamada al orden y facultades disciplinarias.

La llamada a la cuestión se hace cuando un orador se aparta innecesariamente del tema debatido, lo que implica una pérdida de tiempo y una dificultad para seguirle. En este sentido el artículo 102.1 del Reglamento del Congreso afirma: Los oradores serán llamados a la cuestión siempre que estuvieren fuera de ella, ya por digresiones extrañas al punto de que se trata, ya por volver sobre lo que estuviere discutido o votado. En este caso el presidente debe llamarle a la cuestión. El apartado 2 del mismo artículo impone que tras efectuar tres veces este llamamiento el presidente debe retirarle el uso de la palabra.

En la práctica actual no es frecuente hacer llamadas a la cuestión, y ello por las propias características del debate actual. Es difícil que un diputado pueda apartarse mucho del tema debatido, dada la reducida duración de los turnos de palabra. Resulta más práctico — tal como se hace— aguardar a que se consuma el tiempo establecido para instar al orador a la terminación de su discurso. En definitiva este instrumento es más propio de sistemas más abiertos en el uso de la palabra.

La llamada al orden tiene un ámbito de aplicación más extenso y eso favorece su aplicación más frecuente. El artículo 103 prevé que se dirija no solo al orador en uso de la palabra, sino también a cualquier diputado o, incluso personas oyentes en las tribunas ${ }^{53}$. Procede cuando se altere el orden o se interrumpan indebidamente las discusiones, lo que suele producirse mediante improperios, expresiones ofensivas ${ }^{54}$, abucheos o ruidos. En concreto el artículo citado detalla los siguientes casos: 1. Cuando profirieren palabras o vertieren conceptos ofensivos al decoro de la Cámara o a sus miembros, de las Instituciones del Estado o de cualquiera otra

52 Véase E. MAY Treatise on The Law, Privileges, Proceedings and Usage of Parliament» ob. cit. p. 442.

53 Esto último se recoge en el artículo 70.2.

${ }^{54}$ Un reciente ejemplo de este tipo de comportamientos lo tenemos en las palabras ofensivas («que se jodan») lanzadas por una diputada desde su escaño cuando intervenían otros oradores (sesión de 11 de julio de 2012), palabras que no pudieron captarse para su constancia en el Diario de Sesiones pero que en cambio fueron grabadas por video. Tuvieron amplia repercusión en los medios de comunicación social. 
persona o entidad. 2. Cuando en sus discursos faltaren a lo establecido para la buena marcha de las deliberaciones. 3. Cuando con interrupciones o de cualquier otra forma alteraren el orden de las sesiones. 4. Cuando, retirada la palabra a un orador, pretendiere continuar baciendo uso de ella. Obsérvese el tono omnicomprensivo que emplea el número 3 (o de cualquier otra forma alteraren el orden) revelador de que se ha querido poder afrontar toda manifestación de palabra u obra que perturbe las discusiones.

Ahora bien en esta cuestión el presidente tiene un margen de apreciación ${ }^{55}$, pues la tensión del debate puede llevar a pequeñas interrupciones sin la gravedad suficiente como para recurrir a esta vía. La llamada al orden debe reservarse para cuando se produzcan manifestaciones claramente ofensivas para una persona (insultos) o para el propio decoro de la institución (lenguaje soez ${ }^{56}$. Pues semejantes expresiones cargan el debate de agresividad y violencia, dificultando así que sirva a los fines que lo justifican.

Dada la autoridad del presidente y la calidad de las personas a que se dirige, el Reglamento presume tácitamente que el llamado al orden depondrá su actitud, aquietándose con lo que le diga el primero. En la práctica así ocurre: cesación inmediata por el infractor de lo que determina la llamada al orden.

Sin embargo, cabe que se produzca una resistencia a la orden presidencial o que pasado algún tiempo se reitere el comportamiento indebido. En este caso pueden aplicarse las facultades disciplinarias que citábamos en tercer lugar. Así, el artículo 104 dispone que tras ser llamado tres veces en una misma sesión, le será retirada, en su caso, la palabra al orador o diputado y el Presidente, sin debate, le podrá imponer la sanción de no asistir al resto de la sesión. Pero para ello es necesario que la segunda llamada al orden haya incluido la advertencia de estas consecuencias. En caso de no atender esta exigencia, el presidente puede adoptar las medidas pertinentes para hacer efectiva la expulsión, lo que parece referirse al desalojo forzoso. En este caso, adicionalmente, puede prohibirle asistir a la siguiente sesión.

Además, en el caso de proferir expresiones ofensivas, el presidente puede requerir al diputado u orador para que las retire y ordenar que no consten en el Diario de Sesiones. No se dice nada en cambio sobre si esta supresión puede aplicarse a los videos y audios que recogen las sesiones y que obtienen una publicidad parecida a los diarios de sesiones, por cuanto son accesibles en la web de la cámara.

55 En el mismo sentido L. DE LA PEÑA Comentarios al Reglamento del Congreso de los Diputados», ob. cit., p. 744 .

56 Así, respecto a la alteración del orden que se recoge en nota anterior, el Presidente del Congreso, ejercitando esta discrecionalidad, amonestó verbalmente a la diputada Sra. Fabra en su despacho y dio cuenta pública de esto último en la sesión de 17 de julio. véase Diario de Sesiones del Congreso de los Diputados de dicha fecha, núm. 49, p. 3. 
En todo caso, la negativa a retirar las ofensas proferidas podrá dar lugar a sucesivas llamadas al orden, con los efectos ya mencionados.

La última medida disciplinaria prevista (art. 106) es la suspensión en la condición de diputado que puede decretar el presidente cuando se produzca una alteración calificada de grave. Esta suspensión puede durar hasta un mes, pero es posible que el Pleno a propuesta de la mesa amplíe esta sanción siguiendo lo previsto en el artículo 101.

Lógicamente la aplicación de sanción tan grave debe administrarse con mucha prudencia, pues de hecho afecta a un representante popular y puede provocar alteraciones en los equilibrios políticos de la cámara. De hecho, que sepamos, no se ha aplicado nunca desde la transición política.

\section{BIBLIOGRAFÍA CONSULTADA}

- AA.VV., "Comentarios al Reglamento del Congreso de los Diputados», coord. M. ${ }^{a}$ Rosa Ripollés, Congreso de los Diputados, Madrid, 2012.

- ALGUACIL PRIETO, María Luisa, MACIÁ, Mateo, Martínez-Cañavate, María del Rosario, «El Diario de Sesiones del Congreso de los Diputados (1810-1977)». Congreso de los Diputados.

- ARISTÓTELES, Retórica, edición del Centro Estudios Políticos y Constitucionales, Madrid, 1999.

- BAGEHOT, Walter, La constitución inglesa, traducción de A. Posada, estudio preliminar de J. Varela, Centro Estudios Políticos y Constitucionales, Madrid, 2010.

- BENTHAM, Jeremy, Tácticas parlamentarias, reimpresión, Congreso de los Diputados, Madrid, 1991.

- CAZORLA, Luis María, «La oratoria Parlamentaria». Espasa Calpe 1985.

- CAVERO GÓMEZ, Manuel, Sesiones parlamentarias: debate y publicidad en Los Parlamentos de Europa y el Parlamento Europeo, J. M. ${ }^{a}$ Gil-Robles Gil-Delgado (dir.), Proyectos y Producciones Editoriales, Madrid, 1997.

- COSCULLUELA MARTíNEZ, Bárbara, El debate sobre el estado de la nación, en Asociación Profesional de Letrados de las Cortes Generales. «Bicentenario de la Secretaría y del Cuerpo de Letrados de las Cortes 1811-2011». Cortes Generales, Madrid, 2011.

- CUENCA TORIBIO, José Manuel, La oratoria parlamentaria española: una antología Madrid Boletín Oficial del Estado: Centro de Estudios Políticos y Constitucionales, 2002.

- FOLCHI BONAFONTE, Imma, Los debates de política general y monográficos en Asociación Española de Letrados de Parlamentos. Parlamento y control del gobierno : V jornadas de la Asociación Española de Letrados de Parlamentos, F. Pau i Vall (coord.), Aranzadi, Pamplona, 1998. 
- GARCÍA-ESCUDERO MÁRQUEZ, Piedad, «El Procedimiento Legislativo Ordinario en las Cortes Generales» Centro de Estudios Políticos y Constitucionales 2006.

— GENTILE JORGE Horacio, «Derecho Parlamentario» 2. edición actualizada. Ciudad Argentina.

- GIL-ROBLES, José María y PÉREZ-SERRANO, Nicolás, «Diccionario de Términos Electorales y Parlamentarios». Taurus, Madrid, 1977.

- GONZALO, Manuel, La publicidad de los debates de control parlamentario en Asociación Española de Letrados de Parlamentos. Jornadas (2. ${ }^{\text {19 }}$ 1994. Madrid). Parlamento y opinión pública, F. Pau Vall (coord.), Tecnos, Madrid 1995.

- GUITART ESCUDERO, María Pilar, «Discurso Parlamentario y lenguaje políticamente correcto». Congreso de los Diputados 2005.

- HAMILTON, W.G., Lógica parlamentaria, Congreso de los Diputados, Madrid, 1996.

- HERNÁNDEZ GUERRERO José Antonio y GARCÍA TEJERA, María del Carmen, "El arte de hablar». Ariel 2004.

- KRIELE, Martin, Introducción a la teoría del Estado, Ediciones Depalma, Buenos Aires, 1980

- LAÍN ENTRALGO, Pedro, «Parlamento y lenguaje» en Revista de las Cortes Generales n. ${ }^{\circ} 1,1984$.

- LÓPEZ GARRIDO, Diego, Los debates parlamentarios, en Seminario sobre Derecho Parlamentario (1990. Vitoria-Gasteiz). Parlamento y derecho, Alberto Figueroa Laraudogoitia, Juan Carlos da Silva Ochoa (coords.) Parlamento Vasco, Vitoria-Gasteiz 1991.

- LÓPEZ NAVIA, Santiago A., "El arte de hablar bien y convencer». Temas de hoy, Madrid, 2010.

- MANNINO, Armando, «Diritto Parlamentare», Guiffrè Editore, Milán, 2010.

- MARAÑÓN GÓMEZ, Raquel, Dialéctica erística parlamentaria: el debate parlamentario, en Asociación Profesional de Letrados de las Cortes Generales. «Bicentenario de la Secretaría y del Cuerpo de Letrados de las Cortes 1811-2011». Cortes Generales, Madrid, 2011.

- MAY, Erskine, Treatise on The Law, Privileges, Proceedings and Usage of Parliament» Twenty-fourth edition 2011. LexisNexis.

- MEANY, John, On that point!: an introduction to parliamentary Debate International Education Association, New York ; Amsterdam ; Brussels: 2003.

- ORTEGA, Alfonso, «El discurso político», DM, Murcia, 2006.

- PEÑA RODRÍGUEZ, Luis de la, El control parlamentario: debates generales y monográficos, en El Reglamento parlamentario: propuestas de reforma [J. M. Corona Ferrero, Á. L. Sanz Pérez, M. Souto Galván (coords.) Parlamento de Cantabria, Santander, 2000.

- RECODER DE CASSO, Emilio y GARCÍA-ESCUDERO, Piedad, Artículo 80, en Comentarios a la Constitución, dir. Fernando Garrido Falla Civitas, Madrid 2001. 
- SANTAOLALLA, Fernando, «Derecho Parlamentario Español», España Calpe, Madrid, 1990.

- El Parlamento en la encrucijada. EUDEMA, Madrid, 1989

— «El foro parlamentario. Una reflexión sobre las salas de plenos y comisiones en algunos parlamentos europeos», en Bicentenario de la Secretaría y del cuerpo de letrados de las Cortes, Asociación de Letrados de las Cortes Generales, Cortes Generales, Madrid, 2011.

- SCHMITT, Carl, Teoría de la Constitución, Editorial Revistad e Derecho Privado, Madrid, 1934.

- TANDA, Anton Paolo «Dizionario Parlamentare», Editore Colombo, Roma, 1998.

- VEGA DE, Pedro, «El principio de publicidad parlamentaria y su proyección constitucional» en Revista de Estudios Políticos núm. 43, 1985.

— «Las sesiones plenarias de las cámaras» en Comentarios de la Constitución española de 1978, dir. O. Alzaga, Cortes Generales-Edersa, Madrid, 1998, T. VI.

Title:

THE PARLIAMENTARY DEBATE AND THE MANNER OF SPEAKING

\section{Summary:}

1. Importance of parliamentary debate. 2. Reasons for debating. 3. Its consequence: a collegiate body or assembly. 4 . Their usefulness: political forum par excellence; School of freedom and tolerance. 5. The debate demands a vote. 6. The above features differentiate the Parliament from the Government. 7. The procedural differences are expression of the division of powers. 8. Conditions of the parliamentary debate. 9. Manner of speaking. 9.1. Requesting the floor. 9.2. Personal speeches. 9.3 Ban on reading of speeches. 9.4. No interruption. 9.5 Speeches directed to the House or to the Presidency. 10. Precedence in speaking. List of speakers. 11 Use of the seat or the rostrum. 12. Powers of the Chairman

\section{Resumen:}

El debate es la forma de trabajar del Parlamento y lo que a la postre le confiere su rasgo más destacado frente a los otros poderes del Estado. Existe una clara interdependencia entre el carácter representativo y el carácter deliberante del Parlamento. Cumple un papel fundamental e insustituible en la democracia, por lo que debe ser cuidado en ex- 
tremo: la opinión pública puede conocer la actitud de cada partido sobre cada ley y cada problema político. Al mismo tiempo le permite valorar la capacidad y preparación de sus representantes. Constituye una escuela de democracia y tolerancia, al acostumbrar a los ciudadanos a oír con respeto las opiniones ajenas.

El debate debe ser amplio y libre, pero también mínimamente ordenado. A tal fin se dirigen las diversas reglas sobre el uso de la palabra: solicitud de la misma, no interrupción, prohibición de lectura de discursos y otras. El presidente de la Cámara desempeña una función muy destacada para conseguir una participación igualitaria y para evitar excesos en uso de la palabra.

En España el debate es muy restrictivo por cuanto se centra en los portavoces de los grupos, sin apenas ocasión de intervenir para otros parlamentarios. Se permite la lectura de discursos con lo cual se pierde espontaneidad y de resultas merma el interés de los ciudadanos.

\begin{abstract}
:
The debate is the way of working of Parliament and ultimately what gives it its most prominent feature in relation to the other branches of government. There is a clear interdependence between the representative and deliberative character of Parliament. Further it plays an irreplaceable role in democracy, so it must be carefully managed: the public opinion can know the attitude of each party on each law and political problem. At the same time it allows to evaluate the capacity and preparedness of the representatives. It is a school of democracy and tolerance so far it accustoms the public to hear other opinions respectfully. The debate should be broad and free, but also minimally ordered. To this end, various rules govern the manner of speaking: the request of the floor, not interruption, prohibition of reading speeches and others. The Speaker of the House plays an outstanding role to achieve equal participation and to avoid improper use of the floor.

In Spain the debate is very restrictive because it is focused on the spokespersons of the political groups, with little opportunity to speak to other lawmakers. It allows reading speeches thus it loses spontaneity and as a result decrease the interest of citizens.
\end{abstract}

\title{
Palabras clave:
}

Debate; Parlamento; uso de la palabra; oradores; división de poderes.

Key words:

Debate; Parliament; manner of speaking; speakers; separation of powers. 
